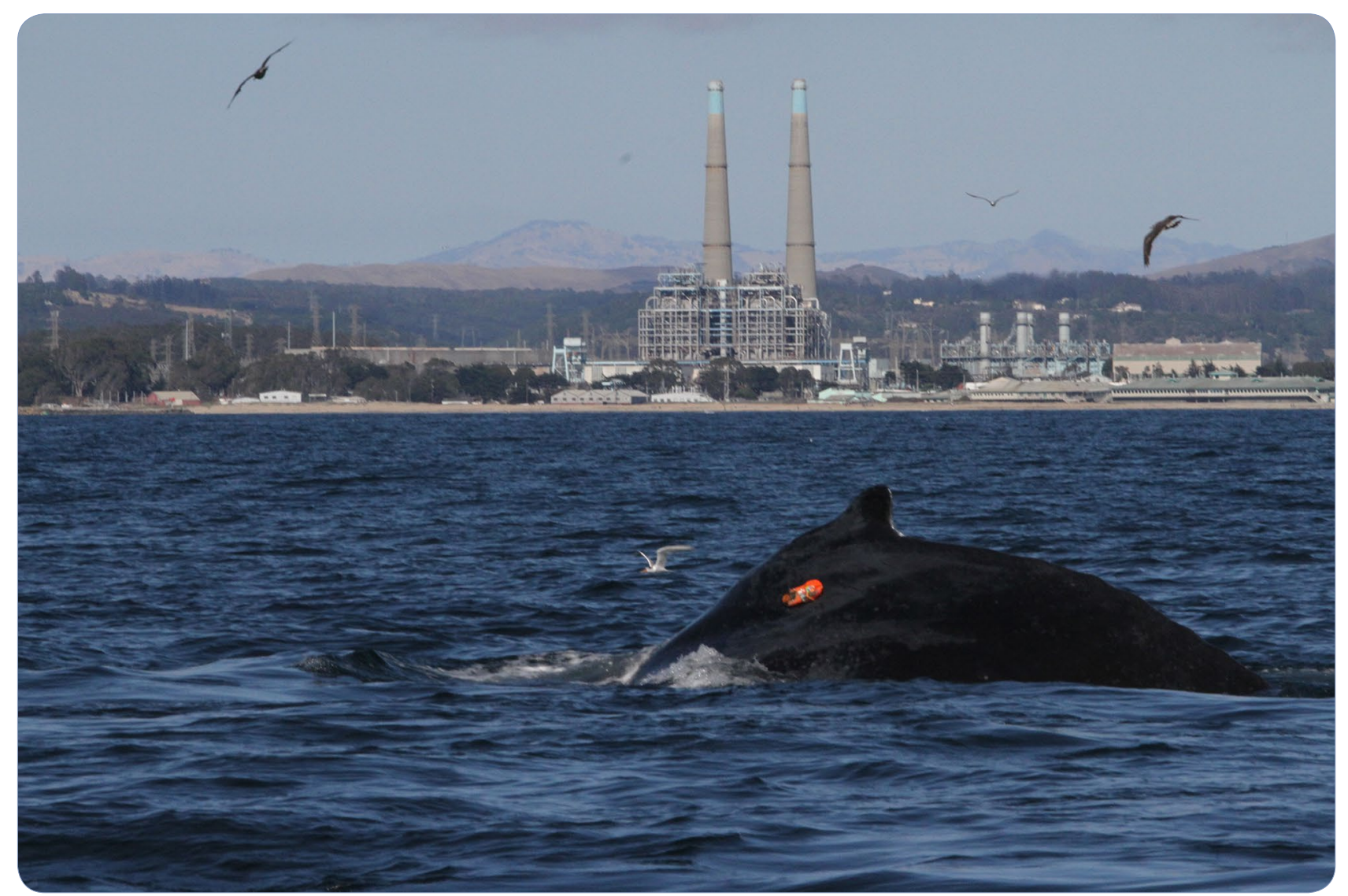

Testing tag attachments to increase the attachment duration of archival tags on baleen whales

Szesciorka et al.

C Biomed Central 


\title{
Testing tag attachments to increase the attachment duration of archival tags on baleen whales
}

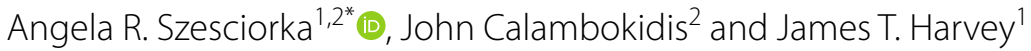

\begin{abstract}
Background: As biologging technology has advanced to study whale behavior, various tag attachment methods have been developed. Suction cup attachments were developed for short-term $(<24 \mathrm{~h})$ studies using high-resolution archival tags, and implantable or dart attachments were developed for long-term (months) studies using coarseresolution satellite tags. The purpose of this study was to test various tag attachment configurations to increase the deployment duration of archival tags while minimizing potential physical impacts to the whale.

Results: From 2013 to 2015, 31 humpback whales (Megaptera novaeangliae) and 20 blue whales (Balaenoptera musculus) were tagged, allowing us to test 10 tag attachment configurations, grouped as suction cup, suction cup with dart, two-dart configurations with petals, four-dart configurations, and four-dart configurations with petals. Durations resulting from four-dart configurations with petals were greater than suction cup tags for humpback whales $(P=0.04)$. Durations resulting from four-dart configurations with petals were greater than all other tag attachment types for blue whales $(P<0.04)$. There was no difference in reaction to tagging by tag attachment type for humpback $(P=0.19)$ or blue whales $(P=0.24)$. Tags attached with titanium darts were recovered with 2 darts $(5 \%)$ lost and 31 petals (14\%) broken, whereas tags attached with stainless steel darts were recovered with 1 dart (3\%) lost and 2 petals (1\%) broken. Re-sights of three tagged animals up to 34 days after tags detached showed no sign of tearing or swelling at the tag site.

Conclusions: Tag attachments using four darts with petals remained on whales the longest with no increase in reaction to tagging by either species. Heat-treated stainless steel darts resulted in equivalent tag attachment durations as titanium darts but with reduced petal breakage. Attachments with four darts, despite creating additional points of entry for potential bacterial transfer, did not produce signs of tearing or swelling on animals re-sighted up to 34 days after tagging. Attaching archival tags with four stainless steel darts with petals on baleen whales will allow for the collection of weeks of fine-scale data, allowing researchers to answer questions about foraging, daily activity, and diel trends.
\end{abstract}

Keywords: Biologging, Long-term tag, Tag development, Baleen whale, Dive behavior

\section{Background}

The first measurement of the maximum dive depth of a marine animal was recorded when a capillary-tube pressure gauge was attached to a fin whale (Balaenoptera physalus) with a harpoon [1]. Since then, biologging

\footnotetext{
*Correspondence: angela@szesciorka.com

${ }^{1}$ Moss Landing Marine Laboratories, 8272 Moss Landing Rd, Moss Landing, CA 95039, USA

Full list of author information is available at the end of the article
}

technology has quickly advanced, integrating GPS, accelerometers, magnetometers, pressure sensors, and acoustic recorders that allow for the collection of biological, environmental, and behavioral information on free ranging marine animals [2-5].

As new tag technology was being introduced, so were methods of tag attachment. Unlike turtles, pinnipeds, and small odontocetes that could be captured and tagged using harnesses, rings, epoxies, and acrylic glues [e.g., 
6-11], large whales could not be captured and their smooth, hairless, and regularly sloughed skin made epoxy or glue methods impossible. This led to the development of tag attachments that could be implanted into the bodies of larger cetaceans using modified crossbows or pneumatic guns $[12,13]$.

Implantable satellite tags allowed for long-term tag deployments (months) on whales, enabling researchers to answer questions about distribution and movement [1315]. However, satellite transmissions can only send small amounts of compressed data at each uplink, which can be affected by the number of satellites present at the time of uplink and how long the animal remains at the surface [16]. Using a combination of transmission to satellites augmented with shore-receiving stations has allowed some transmission of more detailed data [17]. Because bandwidth limitation results in coarse-resolution data, these tags are typically not suitable for fine-scale studies of behavior.

Another direction in tag attachment has been the use of suction cup-attached archival tags that do not penetrate the skin [18]. In addition to being readily available, inexpensive, and easy to attach via crossbow or pole [19], these tags were designed to collect data at high-sampling rates, allowing for the collection of fine-scale information on behavior [16]. The tags needed to be recovered to retrieve the data, so they were not constrained by bandwidth limits like satellite tags. However, because suction cup-attached tags typically remained on for $<24 \mathrm{~h}$, researchers could not answer questions about fine-scale behavior at time scales of days to weeks.

The purpose of this study was to test various tag attachment configurations, including methods typically used with dart-attached satellite tags to increase the deployment duration of archival tags, ultimately allowing for the collection of high-resolution behavior data over intermediate time periods (days to weeks) compared with current suction cup-attached archival tags $(<24 \mathrm{~h})$, while minimizing the potential physical impacts to the whale.

\section{Methods}

\section{Tag attachment development}

The tag attachments tested in this study included various configurations of suction cup (Fig. 1a), darted suction cup (Fig. 1b), two-dart configurations with petals (Fig. 1c), four-dart configurations (Fig. 1d), and four-dart configurations with petals (Fig. 1e). Individual tag attachment materials included two types of suction cup, two Grade 4 titanium darts, and five machinable certified 17-4 PH stainless steel darts (Table 1).

Rigid suction cups came from Canadian Tire (Toronto, ON, USA; Fig. 1a), and semirigid suction cups came from Cetacean Research Technology (Seattle, WA; Fig. 1b).
The short 3-petal and long 6-petal Grade 4 titanium darts (Fig. 2a, b) were manufactured by Wildlife Computers (Redmond, WA, USA) for the Low Impact Minimally Percutaneous External-electronics Transmitter (LIMPET) system, based on designs developed by Russ Andrews [20,21]. Implantable tags were designed to penetrate the fascia and muscle layers of the whale, opening up the possibility of bacterial transfer inside the body leading to inflammation and infection. To reduce potential physical impact on whales, the LIMPET darts do not exceed $8 \mathrm{~cm}$ in length so they do not penetrate beneath the blubber layer, which for humpback whales is $\sim 15 \mathrm{~cm}$ deep [22], whereas implantable tags penetrate into the blubber and into the muscle as deep as $30.5 \mathrm{~cm}[12,13]$. The backwards-facing petals of the titanium darts provided anchoring when the tag penetrated the blubber layer. For both long and short titanium darts, the petals were clipped to roughly two-thirds of their original length and rounded to reduce potential tearing as the darts worked their way out of the animal.

The short, conical, and triangular machinable certified 17-4 PH stainless steel darts were manufactured at Moss Landing Marine Laboratories (Moss Landing, CA, USA; Fig. 2c-e). The long 3- and 6-petal machinable certified 17-4 PH stainless darts (Fig. 2f, g) were manufactured by American Benchmark Machine Works (Olympia, WA, USA). These darts were designed to be similar to the titanium darts from the LIMPET system, but were constructed using stainless steel, which is less brittle than titanium. Welding petals onto the darts adds excess heat to the surface area of petals, creating weaknesses where breakage can occur. To decrease the risk of petal breakage from welding and lessen the effects of elongation (how much the material stretches before breaking), the darts were heat-treated at $1100^{\circ} \mathrm{F}$ for $4 \mathrm{~h}$.

These tag attachment materials were tested in 10 configurations: (1) suction cup (rigid), (2) suction cup (semirigid) with a short conical stainless steel dart, (3) two short ( 3 petals each) titanium darts, (4) two long (6 petals each) titanium darts, (5) four long stainless steel conical darts, (6) four stainless steel triangular darts, (7) two short (3 petals each)/two long (six petals each) titanium darts, (8) four long (6 petals each) titanium darts, (9) four long (3 petals each) stainless steel darts, and (10) four long ( 6 petals each) stainless steel darts. To minimize bacterial transfer and risk of infection, the darts were gas sterilized in ethylene oxide (Sequoia Veterinary Hospital; Redwood City, CA, USA), cleaned in 70 \% rubbing alcohol, and coated with $7.5 \%$ povidone-iodine (Betadine) surgical scrub solution before tagging.

The tag attachment methods were tested by attaching a time-depth recorder (TDR) archival tag (Wildlife Computers; Redmond, WA, USA) below the dorsal fin 

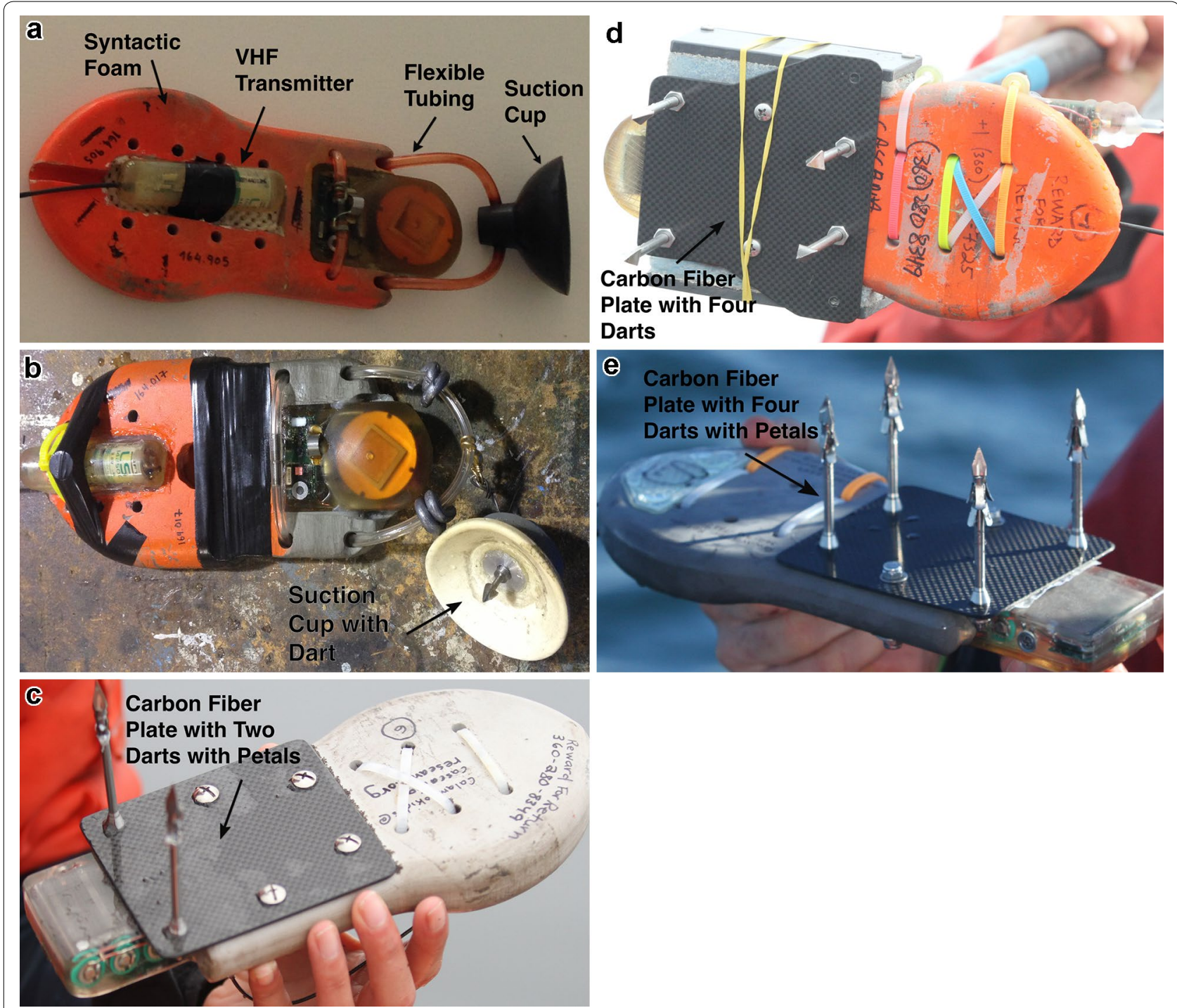

Fig. 1 TDR tags with syntactic foam, radio transmitter and/or satellite tag, and tag attachment. a Suction cup attachment, b suction cup with dart attachment, $\mathbf{c}$ two darts with petals, $\mathbf{d}$ four darts with no petals, and $\mathbf{e}$ four darts with petals

of humpback whales or on the dorsal ridge just forward the dorsal fin of blue whales. Tags were attached as high on each animal as possible to maximize reception of the satellite tag and VHF transmitter. The TDR's dimensions were $102 \mathrm{~mm} \times 56 \mathrm{~mm} \times 30 \mathrm{~mm}$, and they weighed $225 \mathrm{~g}$ in air. The TDRs were glued into a syntactic foam housing for floatation that varied in shape and weight. Total tag weight, including the syntactic foam, VHF, satellite tag, and tag attachment type, ranged from 504 to $652 \mathrm{~g}$.

Because the purpose was to have tags remain attached on whales for days to weeks, recovery could be logistically difficult, especially if the animals vacated the area. Two recovery aids were attached onto the TDR with zip ties. One was a satellite tag (SPOT-258A, Wildlife Computers;
Redmond, WA, USA), which weighed $53 \mathrm{~g}$. The satellite tag was programmed to transmit via the Argos system, providing position estimates within $250 \mathrm{~m}$ when the tag was detached and floating at the water's surface. The second recovery aid was a 10 -g VHF transmitter (Series MM100, Advanced Telemetry Systems Inc.; Isanti, MN, USA). Once within range of the tag's last estimated position, we used the pulse strength of the received radio transmissions through a radio receiver and a three-element folding Yagi antenna (Advanced Telemetry Systems Inc.; Isanti, MN, USA) to locate and recover the tag.

\section{Sample collection}

Tag testing occurred from August 2013 to October 2015 in a number of locations off California, including Bodega, 
Table 1 Dimensions of tag attachment materials for individual suction cup and dart materials

\begin{tabular}{lllllll}
\hline $\begin{array}{l}\text { Individual tag attachment } \\
\text { materials }\end{array}$ & $\begin{array}{l}\text { Cup diameter } \\
(\mathbf{m m})\end{array}$ & $\begin{array}{l}\text { Dart length } \\
(\mathbf{m m})\end{array}$ & $\begin{array}{l}\text { Dart stem } \\
\text { width } \mathbf{( m m})\end{array}$ & $\begin{array}{l}\text { Max width } \\
\text { of dart tip (mm) }\end{array}$ & $\begin{array}{l}\text { Weight of tag } \\
\text { attachment (g) }\end{array}$ & Material \\
\hline Suction cup (rigid) & 77.8 & - & - & - & 68.0 & Rubber \\
Suction cup (semirigid) & 80.9 & - & - & - & 56.7 & Silicone \\
Titanium -short 3-petal dart & - & 45.0 & 3.2 & 6.4 & 4.0 & Grade 4 titanium \\
Titanium-long 6-petal dart & - & 68.0 & 3.2 & 6.4 & 6.0 & Grade 4 titanium \\
Stainless steel-short conical dart & - & 17.5 & 3.2 & 5.6 & 17.0 & $17-4$ PH stainless steel \\
Stainless steel-long conical dart & - & 76.2 & 5.0 & 11.1 & 12.0 & $17-4$ PH stainless steel \\
Stainless steel-triangular dart & - & 76.2 & 5.0 & 9.8 & 11.3 & $17-4$ PH stainless steel \\
Stainless steel-long 3-petal dart & - & 80.0 & 5.0 & 6.0 & 10.0 & $17-4$ PH stainless steel \\
Stainless steel-long 6-petal dart & - & 80.0 & 5.0 & 6.0 & 11.0 & $17-4$ PH stainless steel \\
\hline
\end{tabular}

Half Moon Bay, Monterey Bay, and in the Santa Barbara Channel. Field operations were conducted using two rigid-hull inflatable boats. The tagging boat approached whales to a range of a few meters and deployed the tags with a 3-5-m pole. The secondary boat searched for whales and provided safety support during tagging.

Once a tag was deployed, the reaction of the animal to tagging was noted. Each tagging event also was video recorded. If available, the videos and notes were reviewed to score the reactions to tagging from 1 to 5 (based on increasing severity of reaction) as: (1) no reaction, (2) shallow dip dive, (3) slow dive or slight tail flick, (4) quick acceleration or dive, and (5) hard tail flick. While some whales exhibited multiple reactions, only the strongest reaction was selected for each tagging event.

Photographs of each animal and tag were obtained with an EOS 7D digital single-lens reflex camera and 70-200$\mathrm{mm}$ telephoto zoom lens (Canon; Melville, NY, USA). Fluke and dorsal photographs were used for follow-up monitoring and individual identification based on pigmentation and markings on the underside of the flukes of humpback whales [23] and on the right and left sides of blue whales [24]. For dart-attached tags where adequate photographs were available, tag placement was scored from 1 to 3 (based on how flush the tag was on the animal) as: (1) completely flush, (2) almost flush, and (3) not fully attached. After a tag detached from the animal, the tag floated to the surface and was retrieved after being located using the satellite tag data and VHF receiving gear. Photographs of each tag were taken upon recovery to assess any damage done to the tag or tag attachment system, including petal or dart breakage or bending. Recovery time and location also was noted.

If possible, each animal was followed or re-sighted in successive days to photograph the status of the tag on the animal or the tag site after the tag detached from the animal. Skin and blubber samples were collected, after they sloughed onto the suction cup tags or were removed when the darts detached from the animal, and used for the purpose of sex identification. Photographs taken by whale watch operators during the tagging years also were examined for additional tag site follow-ups.

\section{Data analysis}

Durations of tag attachment were determined from each dive record with Instrument Helper (Wildlife Computers; Redmond, WA, USA). Because sample sizes for the tag attachment configurations were small and not always replicated between species, tag attachment configurations were combined into broader groups for statistical analysis and species were analyzed separately. Humpback whale tag attachment configurations were grouped as suction cup, suction cup with barb, two-dart (with petals), four-dart (no petals), and four-dart (with petals). Blue whale tag attachment configurations were grouped as suction cup, four-dart (no petals), and four-dart (with petals). Due to small sample sizes and because the data violated assumptions necessary for parametric statistics, we used one-way permutational analysis of variances (PERMANOVAs) to test for differences in tag attachment duration and reaction to tagging by tag type for each species. First, we calculated traditional F-statistics on the group means with the built-in 'stats' package in $\mathrm{R}$ [25]. Then, we resampled the data 100,000 times with replacement using the built-in 'base' package in $\mathrm{R}$ and calculated a new F-statistic for each iteration. Lastly, we calculated the probability of obtaining a new F-statistic as large as our original F-statistic to test if there was an effect of tag attachment type on tag attachment duration and reaction to tagging. Post hoc analysis was done with 100,000 pairwise permutational $t$ tests with the 'pairwise.perm.t.test' function from the 'RVAideMemoire' package [26] in R. To account for Type I errors introduced by multiple pairwise tests and Type II errors introduced by small sample 

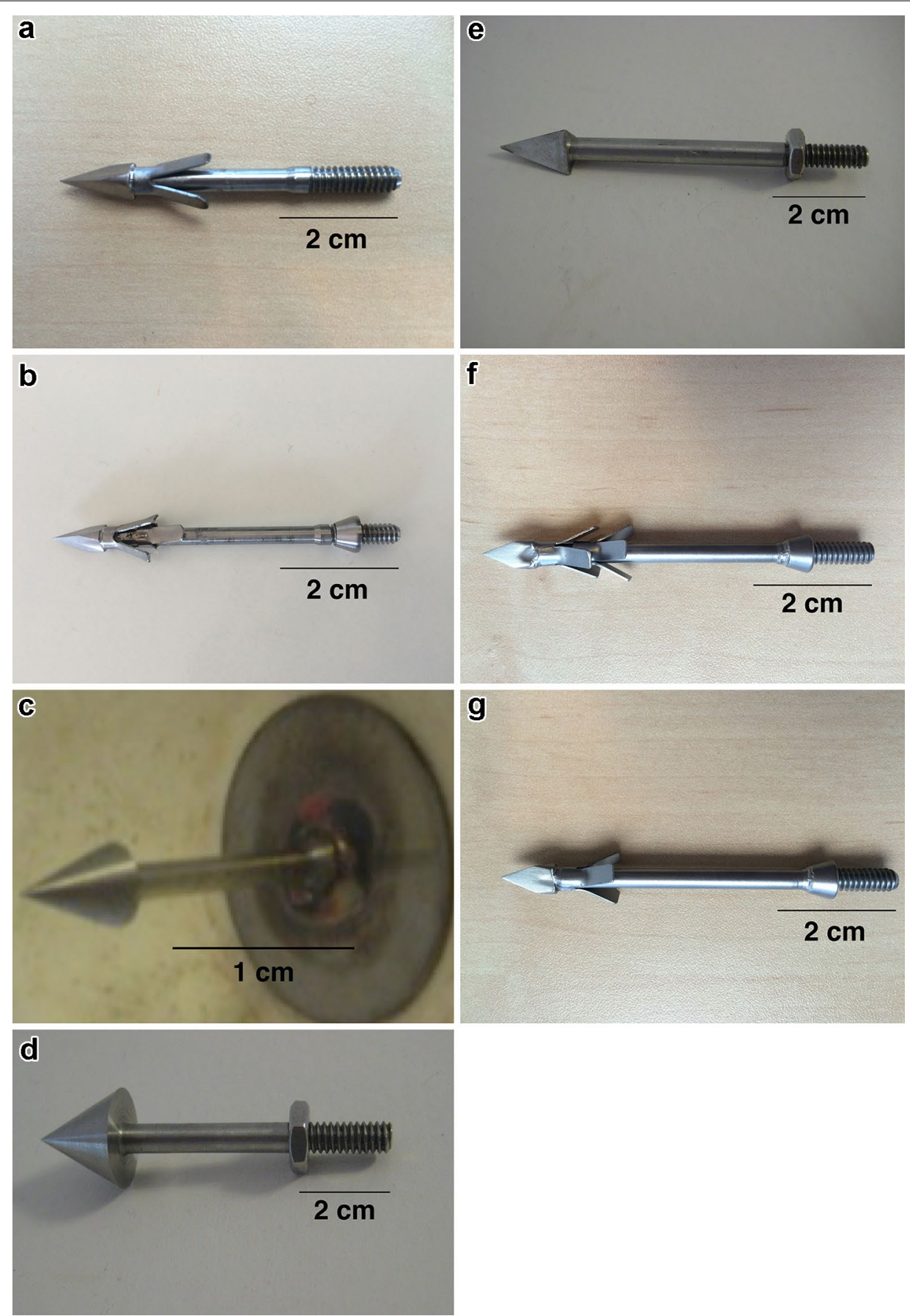

Fig. 2 Titanium and stainless steel darts tested. a Short 3-petal titanium darts with petals clipped and rounded, b long 6-petal titanium darts with petals clipped and rounded, c short conical stainless steel dart used with suction cup, $\mathbf{d}$ long conical stainless steel dart, e triangular stainless steel dart, $\mathbf{f}$ long 6-petal stainless steel dart, and $\mathbf{g}$ long 3-petal stainless steel dart

sizes, we applied the Benjamini and Hochberg False Discovery Rate correction [27] and set statistical significance at $P=0.05$. If available, follow-up photographs of tag attachment sites were analyzed qualitatively to note the healing progress.

\section{Results}

From 2013 to 2015, 31 humpback whales and 20 blue whales were tagged with $10 \mathrm{tag}$ attachment configurations. Tag attachment durations ranged from 0.0 to $393.6 \mathrm{~h}$, and all tag attachment configurations resulted 
in greater median deployment durations on blue whales (Table 2).

In three instances, tags deployed with semirigid suction cups with short conical stainless steel darts $(n=2)$ and long conical stainless steel darts $(n=1)$ penetrated the skin, but did not embed into the blubber layer, pulling out immediately. In three additional instances, tags deployed with stainless steel triangular darts remained attached for less $1.5 \mathrm{~h}$. To minimize unnecessary harm and wasted effort, additional tests with these tag attachment types were not pursued further; however, durations for these deployments were included the analyses.

On four occasions, a tag broke on impact as the tags were being attached to animals. Two occurred with darted suction cups housed in syntactic foam, which broke during tag deployment. Both tags were recovered. The other two instances involved tags with four stainless steel darts. In these cases, the syntactic foam broke in half due to the force of the pole and tag attachment holder on the tag. One of the tags was lost, but in the other case, the carbon fiber plate held the tag together until it was retrieved. Durations for these deployments were also included the analyses.

Durations of tag attachment differed by tag attachment type for humpback whales [PERMANOVA, $F(4,26)=5.33, P=0.007$ ] and blue whales [PERMANOVA, $F(2,17)=59.63, P=0.006]$, rejecting the null hypothesis that all tag attachment types had equal attachment durations. Post hoc analysis using pairwise permutational $t$ tests indicated that durations of tag attachment resulting from four-dart configurations with petals were significantly greater than suction cup tags for humpback whales $(P=0.04$; Fig. 3$)$. Durations from all tag attachments differed for blue whales $(P<0.04$; Fig. 3$)$. Median tag attachment durations were greatest for fourdart configurations with petals for humpback whales [30 h, interquartile range $(\mathrm{IQR})=4.5-45.0 \mathrm{~h}]$ and blue whales ( $187 \mathrm{~h}, \mathrm{IQR}=69.4-329.8 \mathrm{~h}$; Fig. 3 ). There was no significant difference in reaction to tagging by tag attachment type for humpback whales [PERMANOVA, $F(4,23)=1.65, P=0.19$ ] or blue whales (PERMANOVA, $F(2,17)=1.38, P=0.24]$. Although unbalanced tag testing did not allow for a comparison of reaction to tagging by species, humpback whales typically displayed stronger reactions than blue whales (Table 2). Sample sizes were too small for statistical analysis of the effect of tag placement quality on tag attachment duration; however, there was no clear pattern, with one of the greater durations resulting from a tag not fully attached and some of the lesser durations resulting from tags that were completely flush with the animal (Table 2).

Of the 12 deployments with titanium darts with petals, tags were recovered with a total of two darts (5\%) lost and 31 petals (14\%) lost, whereas of the nine deployments with stainless steel darts with petals, tags were recovered with 1 dart $(3 \%)$ lost and 2 petals $(1 \%)$ lost (Table 3). Photographs of the stainless steel dart-attached tag while still attached to the whale indicated the dart came unscrewed from the carbon fiber plate outside of the whale, allowing it to rotate and eventually completely detach from the tag. Because we were not able to resight the two animals that had a titanium dart lost from the tags, we do not know whether the darts remained implanted in the animals; however, there no remnant pieces remained threaded in the carbon fiber plate to indicate dart breakage. The percentage of all recovered darts with one or more petals lost did not differ by species (22\% humpback and $23 \%$ blue whales).

Most (81\%) tags were recovered within $24 \mathrm{~h}$ after the tag detached from the animal. On five occasions, we moved to another region to tag whales and returned within 33 and $84 \mathrm{~h}$ to retrieve the tags. On four occasions, blue whales tagged in the southern California Bight traveled 193-1031 km to the Baja California Peninsula in Mexico before the tags detached. Recovery of those tags was a priority because of the value of the tags, both in the cost of the material and in the added value of weeks of dive data. In these instances, additional time for recovery was needed (1.17-18 days) for logistical planning, including chartering boats and waiting for safe weather, especially following a hurricane in 2015. More than half $(67 \%)$ of the recovered tags yielded skin and blubber samples upon retrieval-18 samples from humpback whales and 16 samples from blue whales.

Three humpback whales were successfully re-sighted in Monterey Bay, CA, USA, and photographed 1-34 days after the tag attachment failed and the tag detached (Fig. 4). Visual assessments and analysis of photographs indicated no evidence of external tearing or swelling at the at the tag attachment site.

\section{Discussion}

We found that tags attached with four-dart configurations with petals resulted in the greatest attachment durations with no difference in reaction to tagging by tag type or by species. The switch to heat-treated stainless steel darts reduced the incidence of petal breakage, likely a combination of using a stronger material and heat-treating to increase material resilience. However, tag attachment duration also could be influenced by a number of additional factors, including tag location, quality of placement, and behavioral differences in species and individuals.

The tags were attached as high up on the animals as possible to maximize satellite and VHF transmission time when the animals came to the surface. However, 


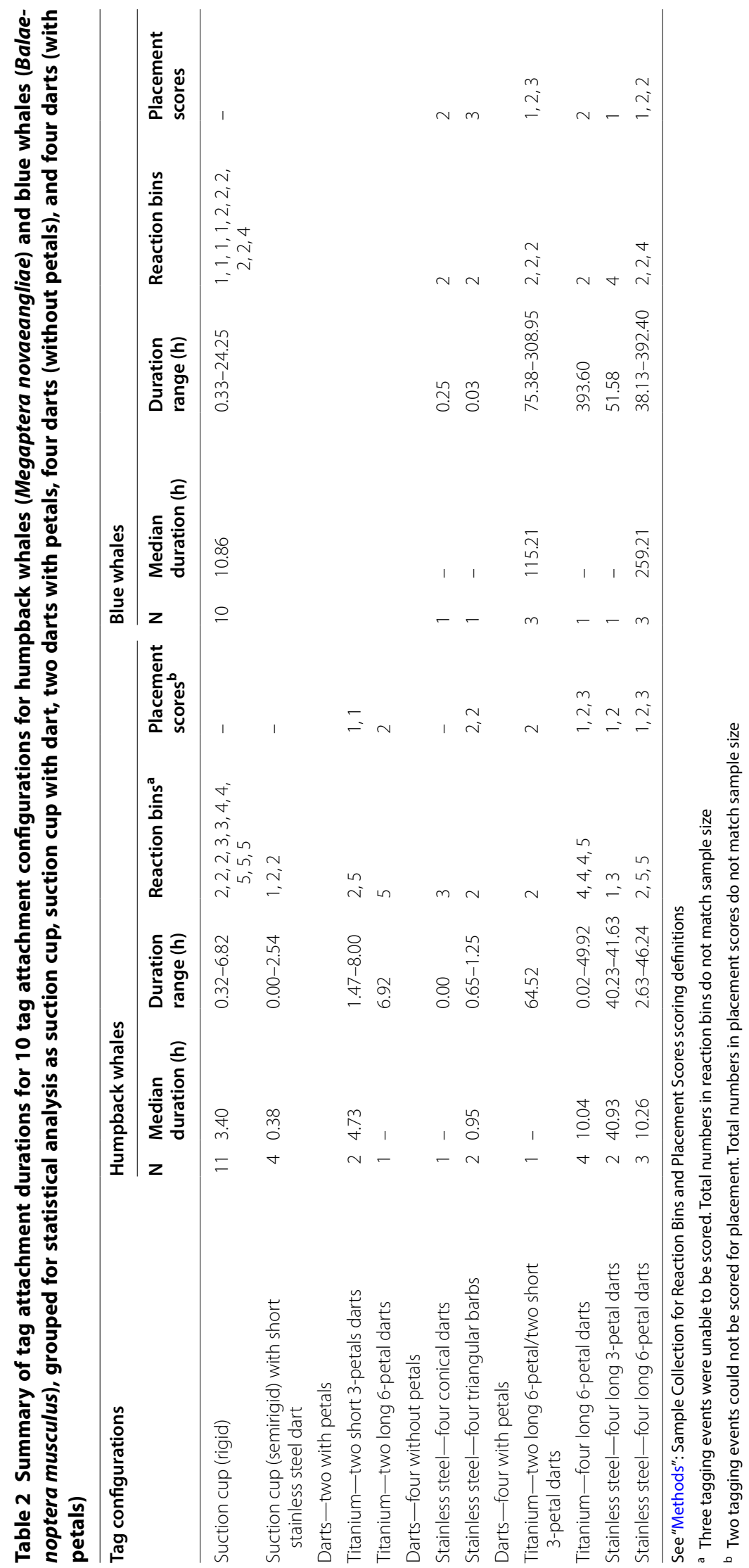



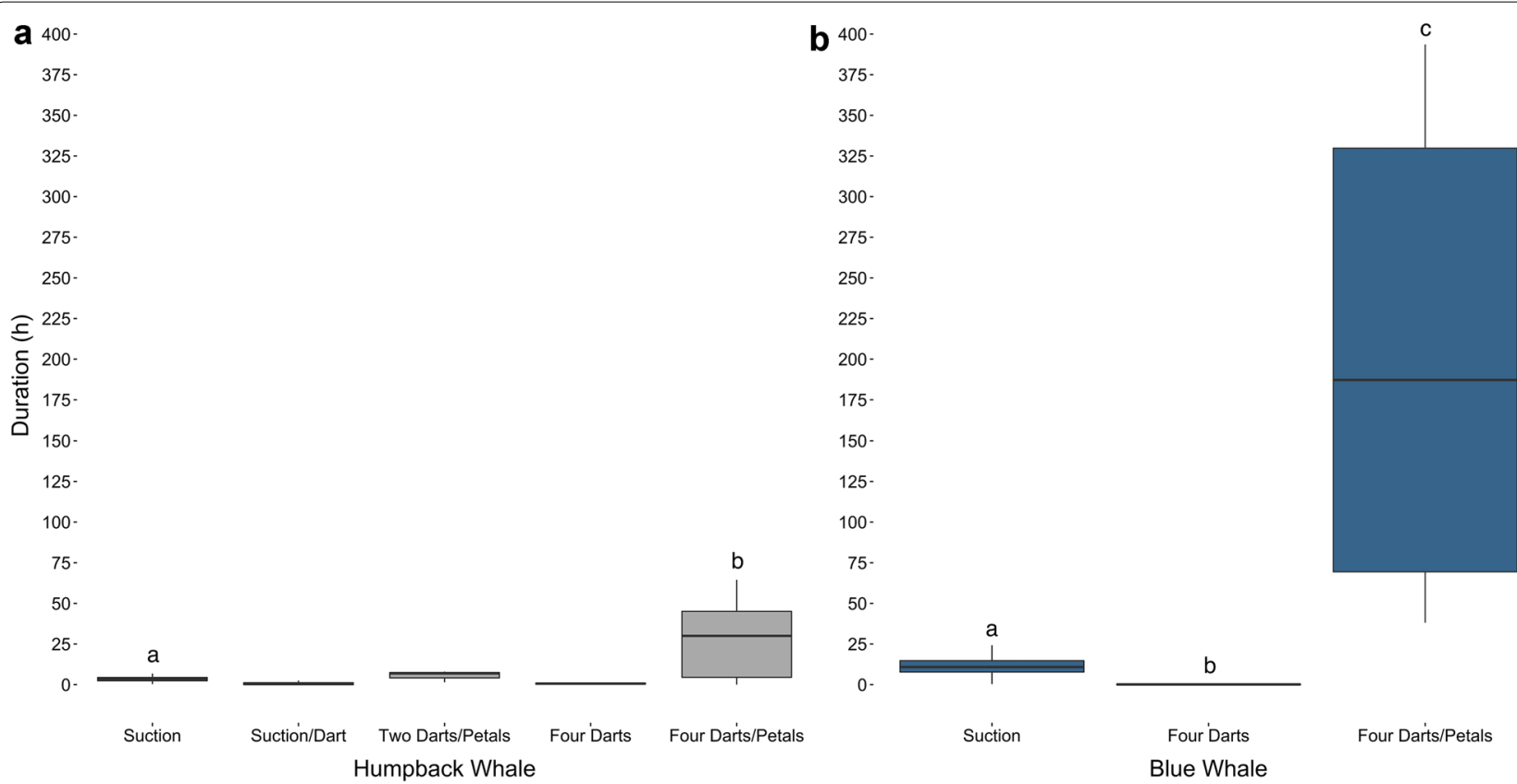

Fig. 3 Box plots showing median tag attachment durations by tag type with first and third quartiles. a Humpback whale (Megaptera novaeangliae) tag configurations (left) were grouped as suction cup, suction cup with dart, two darts (with petals), four darts (no petals), and four darts (with petals). b Blue whale (Balaenoptera musculus) tag configurations (right) were grouped as suction cup, four darts (no petals), and four darts (with petals). Statistical differences from permutational pairwise $t$ test, corrected with the Benjamini and Hochberg false discovery rate, are denoted by different letters

Table 3 Outcome of tags attached with two or four darts titanium or stainless steel darts, including number of tags, darts, and petals deployed and number (percent) lost

\begin{tabular}{lccccc}
\hline & \multicolumn{2}{l}{ Titanium } & & \multicolumn{2}{c}{ Stainless steel } \\
\cline { 2 - 3 } & Deployed & Lost (\%) & & Deployed & Lost (\%) \\
\hline $\begin{array}{l}\text { Tags (2 or 4 darts } \\
\quad \text { with petals) }\end{array}$ & 12 & $0(0 \%)$ & 9 & $0(0 \%)$ \\
Darts & 42 & $2(5 \%)$ & 36 & $1(3 \%)$ \\
Petals & 216 & $31(14 \%)$ & 180 & $2(1 \%)$ \\
\hline
\end{tabular}

the location for tag placement was influenced by tagging conditions such as the boat driver and tagger, sea conditions, and ease of placement, which varies by individual and species. For example, when blue whales surface, there is more surface area, allowing them to be tagged on the dorsal ridge just in front of the dorsal fin. Humpback whales surface in a more arched position, typically only allowing for tag placement closer to the dorsal fin. Another determination factor for tag placement, which has been studied in dolphins but not yet for baleen whales, is selecting the ideal tag location based on tissue location, structure, and strength [28].
The tag at its ultimate location will then be subject to drag forces as the animal moves through the water, and depending on the tag attachment type and quality of the placement, this could further influence tag attachment duration [29]. Tag attachment configurations with two or more darts all need to penetrate the skin in order to be flush with the animal. If the tag is not fully flush, the tag also will likely be pulled out faster due to drag forces and the animal's movement. A number of short-duration tag events were attributed to tags not being flush with the animal. However, some of the greater tag attachment durations resulted from tags that were not flush with the animals. Follow-up photographs of these tags on the animals showed the tags becoming more flush with the animals over time, potentially due to water flow or contact with other animals.

Finally, a difference in foraging strategies of tagged animals could also play a role in tag attachment duration. Whereas blue whales feed almost exclusively on krill (euphausiid spp.; [30]), humpback whales exhibit prey switching, feeding on dense concentrations of krill and schooling fish such as anchovy (Engraulis mordax), herring (Clupea spp.), sardine (Sardinops sagax), capelin (Mallotus villosus) and sand lance (Ammodytes spp.; [e.g., 31]). When feeding on fish, humpback whales tend to travel at greater speeds, make more exaggerated bending 


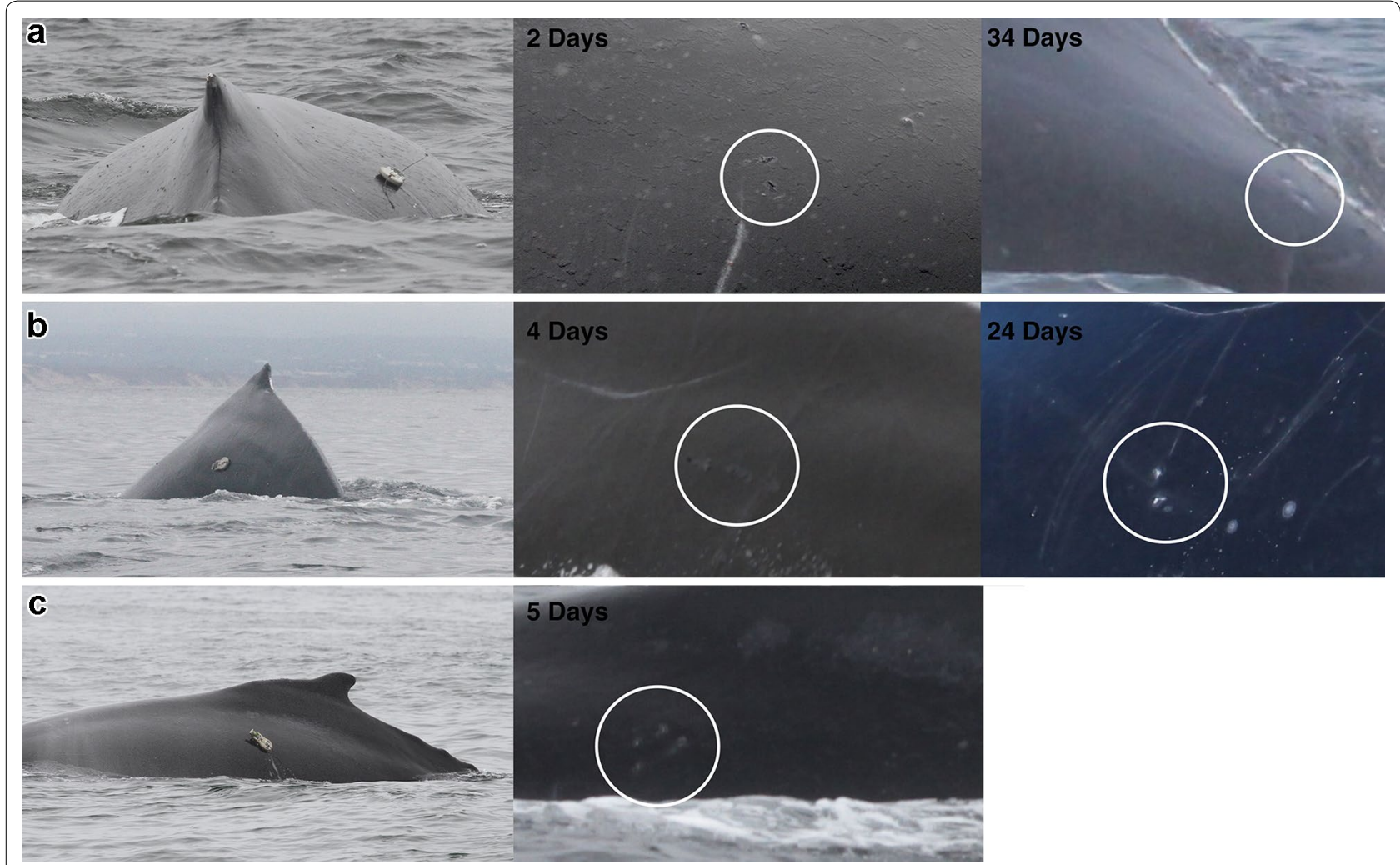

Fig. 4 Photographic follow-ups with tagged whales. a Whale 20140601-6 tagged with two short (3 petals) titanium darts and again 2 and 34 days after tagging. b Whale 20140603-6 tagged with two long (6 petals) titanium darts and again 4 and 24 days after tagging. c Whale 20140604-5 tagged with two short ( 3 petals) and two long ( 6 petals) titanium darts and again 5 days after tagging

and flexing movements, and usually feed in groups where whale-to-whale contact is common [32, 33]. Surface feeding can create additional drag forces from 2.5 to 5 times greater than animals at depth [34,35]. Although we did not quantify prey during tagging, we observed tagged humpback whales feeding on fish. These differences in behavior due to foraging strategy could have influenced the duration that tags remained on humpback whales compared with duration on blue whales.

Response of animals to tagging with dart-attached tags did not elicit responses stronger than tagging with suction cup-attached tags. Reactions ranged from no reaction to a hard tail flick. The range of reactions noted in this study are consistent with the variability in reactions found within and among other species in a number of previous studies [3, 36-39]. For example, Hooker et al. [38] found no difference in observed response to tag deployments compared with biopsy sampling of northern bottlenose whales (Hyperoodon ampullatus) and that the behavioral state of the animal influenced the magnitude of the reaction. Watkins [39] noted that fin whales showed no reaction or moved away after being tagged; humpback whales had no reaction, swam faster, or fluked and dove quickly. Mate et al. [13] noted the reactions of seven species of large whale to tagging, including reactions as mild as head and fluke lifts, to evasive swimming behavior, quick dives, and fluke swishes. In these other studies, the researchers noted that the responses to tagging were short-term, as was the case with this study.

There have been few studies documenting healing following tagging of large whales, especially with LIMPET and similarly designed darts. In developing early implantable radio tags, Watkins et al. [12] found no signs of infection or tissue reaction at four tag-related wound sites 16-18 days post-attachment for humpback or fin whales. Mate et al. [13] found that 40 re-sighted whales tagged between 1990 and 2005 exhibited varying levels of swelling or scarring at the tag site from implantable satellite tags; however, none were in poor health or showed signs of tissue sloughing at the tag site. Gendron et al. [40] found extended periods of swelling when portions of implantable tags remained embedded in tagged blue whales. Best et al. [41] reported scarring, but no swelling or difference in calving rates in re-sighted southern right whales (Eubalaena australis) that were tagged with implantable satellite tags. Similar to these studies, 
follow-up photography of the site of tag attachment on humpback whales up to 34 days after tagging indicated that the wounds exhibited no sign of tearing or swelling, suggesting the modified darts had minimal physical impacts to the whales.

The four-dart configurations used in this study created additional penetration points, each with the potential to allow for bacterial transfer inside the body [42]. However, the darts were small in width and length, thus limiting the depth of penetration into the blubber. Had the darts extended into the axial muscle, similar to implantable satellite tags, they would have been subject to the internal shearing forces between the blubber and muscle layers, creating deeper wounds in the blubber $[40,43]$.

The tags also presented an opportunity to collect tissue samples. Although this is not a replacement for traditional biopsy methods, the collection of skin and blubber from suction cups and darts after the tags detached allowed us to lessen our physical contact with tagged whales by not using traditional biopsy methods for this study. Tags retrieved up to 18 days after release from the animal yielded tissue samples that are being analyzed by Southwest Fisheries Science Center for the purpose of sex identification.

\section{Conclusions}

This study tested various tag attachment configurations to increase deployment duration of archival tags on large whales while minimizing potential physical impacts to whales. Tags with four-dart configurations with petals resulted in the longest attachment durations on humpback and blue whales. The switch to heat-treated stainless steel allowed for the same tag attachment durations as titanium, but with reduced dart or petal breakage. Follow-ups with three tagged humpback whales indicated that the dart-attached tags created small wounds that showed no sign of tearing or swelling up to 34 days after tags detached. The use of dart-attached archival tags has presented new opportunities to collect highresolution data over intermediate (weeks) time periods. Although archival tags need to be recovered, these tags can include a suite of high-sampling kinematic, acoustic, and environmental sensors. Using intermediate-term dart-attached archival tags, we can answer questions about foraging efficiency, daily diving and transit activity, and diel trends.

\footnotetext{
Abbreviations

ARGOS: Advanced Research and Global Observation Satellite; C: celsius; GPS: global positioning system; LIMPET: low impact minimally percutaneous external-electronics transmitter; MLML: Moss Landing Marine Laboratories; SPOT: SPOT-257A satellite tag; TDR: time-depth recorder; VHF: very high frequency.
}

\section{Authors' contributions}

AS, JC, and JH were involved in conception, study design, data collection and interpretation of the findings. AS collected and analyzed the data and was involved in laboratory analyses. AS, JC, and JH prepared the manuscript. All authors read and approved the final manuscript.

\section{Author details}

${ }^{1}$ Moss Landing Marine Laboratories, 8272 Moss Landing Rd, Moss Landing, CA 95039, USA. ${ }^{2}$ Cascadia Research Collective, 218 1/2 4th Ave W, Olympia, WA 98501, USA.

\section{Acknowledgements}

We thank Bill Watson and Kris Machado (MLML), for initial developments of tag attachment devices tested in this study. Thank you also to American Benchmark Machine Works, especially Steve Jacobson and Jesse Brown, for creating stainless steel barbs and plates for the tags. We also want to acknowledge Russ Andrews and Greg Schorr for ideas and discussions on dart design. Thank you to the many volunteers that helped with tagging, especially James Fahlbusch for his vital assistance in the field, Alison Stimpert for field assistance and manuscript edits, Robin Baird for manuscript edits, and Nathan Harrison for assisting in some of the tag preparations.

\section{Competing interests}

The authors declare that they have no competing interests.

\section{Availability of data and materials}

The datasets analyzed during the current study are available from the corresponding author on reasonable request.

\section{Ethics approval and consent to participate}

All procedures performed were in accordance with the ethical standards under MLML's and Cascadia Research's Institutional Animal Care and Use Committee protocols (\#937 and \#AUP-6, respectively), MLML's and Cascadia Research's National Marine Fisheries Service Authorizations and Permits for Protected Species (\#15271 and \#16111, respectively), and MLML's National Oceanic and Atmospheric Administration Office of National Marine Sanctuaries multi-sanctuary research permit (\#MULTI-2013-006).

\section{Funding}

This research was funded by the Office of Naval Research [Grant No. N0001413-1-0772 to JC and Grant No. N00014-09-1-0632 to JH]. Additional funding came from the American Cetacean Society, San Francisco Chapter; American Cetacean Society, Monterey Bay Chapter; California State University Council on Ocean Affairs, Science and Technology; Dr. Earl Myers and Ethel M. Myers Oceanographic and Marine Biology Trust; California Professional Employer Organization; San Jose State University; David and Lucile Packard Foundation; and Moss Landing Marine Laboratories [to AS].

Received: 13 April 2016 Accepted: 1 September 2016

Published online: 22 September 2016

\section{References}

1. Scholander P. Experimental investigations on the respiratory function in diving mammals and birds. Hvalradets Skrifter. 1940;22:1-131.

2. Kooyman GL. Genesis and evolution of bio-logging devices: 1963-2002. Mem Natl Inst Polar Res Ser. 2004;58:15-22.

3. Johnson M. Aguilar de Soto N, Madsen PT. Studying the behaviour and sensory ecology of marine mammals using acoustic recording tags: a review. Mar Ecol Prog Ser. 2009;395:55-77.

4. Hazen EL, Maxwell SM, Bailey H, Bograd SJ, Hamann M, Gaspar P, Godley BJ, Shillinger GL. Ontogeny in marine tagging and tracking science: technologies and data gaps. Mar Ecol Prog Ser. 2012;457:221-40.

5. Goldbogen JA, Friedlaender AS, Calambokidis J, McKenna MF, Simon $M$, Nowacek DP. Integrative approaches to the study of baleen whale diving behavior, feeding performance, and foraging ecology. Bioscience. 2013:63:90-100.

6. Norris KS, Evans WE, Ray GC. New tagging and tracking methods for the study of marine mammal biology and migration. In: Shevill WE, editor. 
The whale problem: a status report. Cambridge: Harvard University Press; 1974.

7. Frost KJ, Lowry LF, Nelson RR. Radiotagging studies of belukha whales (Delphinapterus leucas) in Bristol Bay. Alaska Mar Mamm Sci. 1985;1:191-202.

8. Scott MD, Wells RS, Irvine AB, Mate BR. Tagging and marking studies on small cetaceans. In: Leatherwood S, Reeves RR, editors. The bottlenose dolphin. San Diego: Academic Press; 1990.

9. Jeffries SJ, Brown RF, Harvey JT. Techniques for capturing, handling and marking harbour seals. Aquat Mamm. 1993;19:21-5.

10. Burgess WC, Tyack PL, Le Boeuf BJ, Costa DP. A programmable acoustic recording tag and first results from free-ranging northern elephant seals. Deep-Sea Res Part II. 1998;45(7):1327-51.

11. Fossette S, Ferraroli S, Tanaka H, Ropert-Coudert Y, Arai N, Sato K, Naito Y, Le Maho Y, Georges JY. Dispersal and dive patterns in gravid leatherback turtles during the nesting season in French Guiana. Mar Ecol Prog Ser. 2007;338:233-47.

12. Watkins WA, Schevill WE. The development and testing of a radio whale tag. Woods Hole: Woods Hole Oceanographic Institution; 1977.

13. Mate $B$, Mesecar $R$, Lagerquist $B$. The evolution of satellite-monitored radio tags for large whales: one laboratory's experience. Deep-Sea Res Part II. 2007:54(3-4):224-47.

14. Mate BR, Krutzikowsky GK, Winson MH. Satellite-monitored movements of radio-tagged bowhead whales in the Beaufort and Chukchi seas during the late-summer feeding season and fall migration. Can J Zool. 2000;78:1168-81.

15. Lagerquist BA, Mate BR, Ortega-Ortiz JG, Winsor M, Urban-Ramirez $J$. Migratory movements and surfacing rates of humpback whales (Megaptera novaeangliae) satellite tagged at Socorro Island, Mexico. Mar Mamm Sci. 2008;24:815-30.

16. Hooker SK, Baird RW. Diving and ranging behaviour of odontocetes: a methodological review and critique. Mamm Rev. 2001;31(1):81-105.

17. Schorr GS, Falcone EA, Moretti DJ, Andrews RD. First long-term behavioral records from Cuvier's Beaked Whales (Ziphius cavirostris) reveal recordbreaking dives. PLoS One. 2014. doi:10.1371/journal.pone.0092633.

18. Goodyear J. A new radio tag; the Remora, and behavior of a humpback whale (Megaptera novaeangliae). J Cetacean Res. 1981;2:1-2.

19. Baird RW. Studying diving behavior of whales and dolphins using suction-cup attached tags. Whalewatcher: J Am Cetac Soc. 1998;31 (1):3-7.

20. Andrews RD, Pitman RL, Ballance LT. Satellite tracking reveals distinct movement patterns for Type $B$ and Type $C$ killer whales in the southern Ross Sea, Antarctica. Polar Biol. 2008;31:1461-8.

21. Andrews RD. Improving attachments of remotely-deployed dorsal finmounted tags: tissue structure, hydrodynamics, in situ performance, and tagged-animal follow-up. Seattle: Office of Naval Research; 2011. ONR Report Award Number: N000141010686.

22. Clapham PJ. Humpback Whales. Stillwater: Voyageur Press; 1996.

23. Katona S, Baxter SB, Brazier O, Kraus S, Perkins J, Whitehead H. Identification of humpback whales by fluke photographs. In: Winn HW, Olla BL, editors. Behavior of marine animals. Volume 3. Cetaceans. New York: Plenum Press; 1979.

24. Sears R. The photographic identification of individual blue whales Balaenoptera musculus in the Sea of Cortez. Cetus. 1987;7(1):14-7.

25. R Core Team. R: A language and environment for statistical computing. R Foundation for Statistical Computing, Vienna, Austria. 2016; https:// www.R-project.org/.

26. Maxime Hervé. RVAideMemoire: Diverse Basic Statistical and Graphical Functions. R package version 0.9-55. 2016; https://CRAN.R-project.org/ package $=$ RVAideMemoire.
27. Benjamini Y, Hochberg Y. Controlling the false discovery rate: a practical and powerful approach to multiple testing. J R Stat Soc B. 1995;57:289-300.

28. Andrews RD, Baird RW, Schorr GS, Mittal R, Howle LE, Hanson MB. Improving attachments of remotely-deployed dorsal fin-mounted tags: tissue structure, hydrodynamics, in situ performance, and tagged-animal follow-up. Seattle: Office of Naval Research; 2015. ONR Report Award Number: N000141010686.

29. Shorter KA, Murray MM, Johnson M, Moore M, Howle LE. Drag of suction cup tags on swimming animals: modeling and measurement. Mar Mamm Sci. 2014;30:726-46.

30. Croll DA, Tershy BR, Hewitt RP, Demer DA, Fiedler PC, Smith SE, Armstrong W, Popp JM, Kiekhefer T, Lopez VR, Urban J, Gendron D. An integrated approach to the foraging ecology of marine birds and mammals. DeepSea Res Pt II. 1998:45:1353-71.

31. Wiley D, Ware C, Bocconcelli A, Cholewiak D, Friedlaender AS, Thompson $M$, Weinrich M. Underwater components of humpback whale bubble-net feeding behaviour. Behaviour. 2011;148(5-6):575-602.

32. Ware C, Friedlaender AS, Nowacek DP. Shallow and deep lunge feeding of humpback whales in fiords of the West Antarctic Peninsula. Mar Mamm Sci. 2011;27(3):587-605.

33. Simon M, Johnson M, Madsen PT. Keeping momentum with a mouthful of water: behavior and kinematics of humpback whale lunge feeding. J Exp Biol. 2012;215:3786-98.

34. Blake RW. Biological implications of the hydrodynamics of swimming at or near the surface and in shallow water. Bioinspir Biomim. 2009:4:1-9.

35. Goldman JA. Effects of the free water surface on animals that jump out of the water. Ph.D. thesis, Duke University, Durham, NC; 2001.

36. Schneider K, Baird RW, Dawson S, Visser I, Childerhouse S. Reactions of bottlenose dolphins to tagging attempts using a remotely-deployed suction-cup tag. Mar Mamm Sci. 1998;14:316-24.

37. Stimpert AK, Matilla D, Nosal E, Whitlow WLA. Tagging young humpback whale calves: methodology and diving behavior. Endanger Spec Res. 2012;19:11-7.

38. Hooker SK, Baird RW, Al-Omari S, Gowans S, Whitehead H. Behavioral reactions of northern bottlenose whales (Hyperoodon ampullatus) to biopsy darting and tag attachment procedures Fish. Bull. 2001;99:303-8.

39. Watkins WA. Reaction of three species of whales Balaenoptera physalus, Megaptera novaeangliae, and Balaenoptera edeni to implanted radio tags. Deep-Sea Res. 1981;28(6):589-99.

40. Gendron D, Martinez Serrano I, Ugalde de la Cruz A, Calambokidis J, Mate B. Long-term individual sighting history database: an effective tool to monitor satellite tag effects on cetaceans. Endang Species Res. 2015;26:235-41.

41. Best PB, Mate B, Lagerquist B. Tag retention, wound healing, and subsequent reproductive history of southern right whales following satellitetagging. Mar Mamm Sci. 2015;31:520-39.

42. Weller DW. Report of the large whale tagging workshop. San Diego: U.S Marine Mammal Commission; 2008

43. Moore M, Andrews R, Austin T, Bailey J, Costidis A, George C, Jackson K, Pitchford T, Landry S, Ligon A, McLellan W, Morin D, Smith J, Rotstein D, Rowles T, Slay C, Walsh M. Rope trauma, sedation, disentanglement, and monitoring-tag associated lesions in a terminally entangled North Atlantic right whale (Eubalaena glacialis). Mar Mamm Sci. 2013;29:E98-113. 